\title{
Substance use patterns among university students in Egypt
}

\author{
Manar Khafagy ${ }^{1}$, Zeinab Gomaa ${ }^{2}$ and Mohamed Elwasify ${ }^{2^{*}}$
}

\begin{abstract}
Background: In the past few years, there has been an expanding global interest in the problem of substance use. A variety of studies conducted within the past decade have investigated the prevalence of substance use among university students. The study aimed to detect the prevalence and associates of substance use among Egyptian students at Mansoura University. This cross-sectional, questionnaire-based, observational study was conducted during the period from February to July 2019 on 1138 university students at Mansoura University in Egypt. The university students were randomly divided into three classes (medical, practical, and theoretical). The data were assembled using questionnaires of sociodemographic, clinical attributes, and drug use disorders identification test (DUDIT).

Results: Lifetime substance use among students was 6.5\%. Of the users, 18 (24.3\%) used cannabis, 14 (18.9\%) used tramadol, 10 (13.5\%) used alcohol, 5 (6.8\%) used benzodiazepines, and 1 (1.4\%) used heroin. Only 35.1\% used polysubstance, of those, 10 (13.5\%), 12 (16.2\%), 3 (4.1\%), and 1 (1.4\%) used cannabis and tramadol; cannabis and alcohol; cannabis and inhalant; and cannabis, alcohol, and tramadol respectively. There was a substantial association between substance use and male sex, age above 20 years, smoking, and living in urban areas. In the group that used substances, 50 (4.4\%) suffered substance-related problems and 6 (0.5\%) encountered dependency.

Conclusion: In total, using the mono substance is more than using poly substances in which cannabis, tramadol, and alcohol were the most often utilized substances. The highest percentage of drug-related problems was among medical students while dependence was highest among practical students. These results should be considered in future substance preventive programs.
\end{abstract}

Keywords: Substance, University, Students, Patterns, Egypt

\section{Background}

Substance-related problems are considered one of the global persistent problems endangering humans of the various stage, social milieu, geographical region, educational level, and nationality. Substance use is classified as the continual use of substances, illicit drugs, or the misappropriation of medicine or over-the-bench drugs with adverse outcomes [1].

Substance use has persisted to grow worldwide. In 2016, a total population of about 275 million citizens utilized an illicit substance at least one time. Although

\footnotetext{
* Correspondence: Drwasify_moh@mans.edu.eg; Drwasify2006@yahoo.com

${ }^{2}$ Psychiatry Department, Faculty of Medicine, Mansoura University, Mansoura 35516, Egypt

Full list of author information is available at the end of the article
}

usage is documented throughout all age classes, the peak use is between 25 to 39 years of age, and cannabis was the highest used stuff within the age of 19 years; stimulants were also encountered [2].

A national survey performed over 106,480 Egyptian subjects between 20 and 45 years from different regions found that $13.3 \%$ used the substance at least once in their lives [3]. Furthermore, in 2012, WHO stated that $6 \%$ to $8 \%$ of the Egyptians consumed cannabis. The pattern of substance-related problems was tremendously increasing especially after Arab Spring, 2011 [4].

As utilizing substances may begin before the stage of university studies, a large cohort study done in Egypt involved 10,648 secondary school students concluded that cigarette smoking was the highest, comprising $9 \%$ of 
substance users, 5.1\% used benzodiazepines, $3.3 \%$ used alcohol, 3.1\% used organic solvents, and 2.6\% used cannabis in the past 12 months. The dependence was $0.9 \%$ excluding nicotine. Males had higher independence, regular use, and intake [5].

Substance use during university is linked to a cloud of deleterious concerns from legitimate difficulties, involvement in risky behaviors, development of psychiatric disorders, inappropriate sexual behaviors and academic difficulties, and even to increased rates of injury and death. Significant discrepancies were found between university students and non-university students regarding the type and level of consumption of substance use. Athletes, sexual minorities, students who suffered depression and anxiety, and white men appear to be at special threat for substance use during university [6].

Overall, cannabis and its derivatives were the most used substances among university students in Egypt, Arab countries (Kuwait and Sudan) [7-9], and American and European populations [10, 11]. This can be explained by the recent trend of using new types of synthetic cannabis derivatives, as well as the ongoing debate over cannabis legalization [12]. The usage of alcohol was on the top among the same group as seen in the following studies $[6,13,14]$.

In the USA, the level of substance use is growing among those aged 18 to 25 years, with many of them being new-found clients. In this age group, the regular use of cannabis was estimated by 2.6 million consumers, whereas 3.4 million (10\%) had alcohol use disorders [15]. In Europe, approximately 19.1 million young adults aged 15-34 consumed substances in 2018; men used substances twice as much as women and cannabis was the most extremely abused substance [16]. In Africa, studies discovered a prevalence of drug use between 27.5 and $62 \%[17,18]$.

Regarding the research on substance use during university study in Egypt, few of these studies were performed on male [19] students while others on female students [20] but the majority were conducted on both genders $[7,13,21]$. Only a few of the previous studies demonstrated the pattern and risk factors of substance use in university students while the majority just reported if there was substance intake or not.

\section{Aim of this study}

The present study aimed to assess the prevalence of substance use and its related factors among Mansoura University students, Egypt.

\section{Methods}

\section{Study design}

A cross-sectional observational study was conducted at Mansoura University, Egypt, from February to July 2019.

\section{Subjects}

The target population was Egyptian students, 17 to 25 years old, including both males and females of all educational years from Medicine, Veterinary Medicine, Science, Engineering, Arts, and Education programs. Non-Egyptian students and those who refused to complete the study were excluded.

\section{Sample size calculation}

The sample size was calculated using the Medical program. A previous study in Sohag University students revealed that the prevalence of substance use was 5\% [13]. With alpha error of $5 \%$, beta error of $20 \%$ (i.e., study power $80 \%$ ), and $3 \%$ precision, the sample size was multiplied by two to compensate for the design defect for the cluster sampling method, so the total sample size was 1138. The total number of Egyptian students at Mansoura University during the academic year 2018/ 2019 was 11,4604 students with uneven distribution among the targeted educational programs (Medicine, Veterinary Medicine, Science, Engineering, Arts, and Education). Thus, clustered sampling technique was used. Accordingly, the minimum required sample size was 219 students from medical faculties (146 from medicine and 73 from veterinary), a total of 260 students from practical ones such as engineering (178) and science (82), and 695 students from theoretical faculties such as arts (370) and education (289). This is illustrated in Fig. 1.

\section{Procedure and data collection}

Several clusters (section of academic stage or clinical round) were selected from each grade, and the systematic random method was used. The questionnaires were delivered to students in their classrooms after their sections or clinical rounds.

The questionnaire was designed to gather the following socio-demographic data: Personal data, such as age, sex, year of education, height, weight, physical exercise, consumption of caffeinated beverages, working during the study, marital status, studying hours per day, smoking, health problems, and student's residence during the study.

The DUDIT [22] was constructed to help check for substance use problems and dependence as well as screen out those who do not have such problems. It was done compared to the alcohol use disorders identification test (AUDIT) [23] developed by the World Health Organization (WHO). There are eleven items in the DUDIT questionnaire about the regularity of drug use, detrimental outcomes of drug use, and indications of reliance. DUDIT serves as an applicable screening method used to detect individuals who have a substance-related problem or dependence. Drug-related 


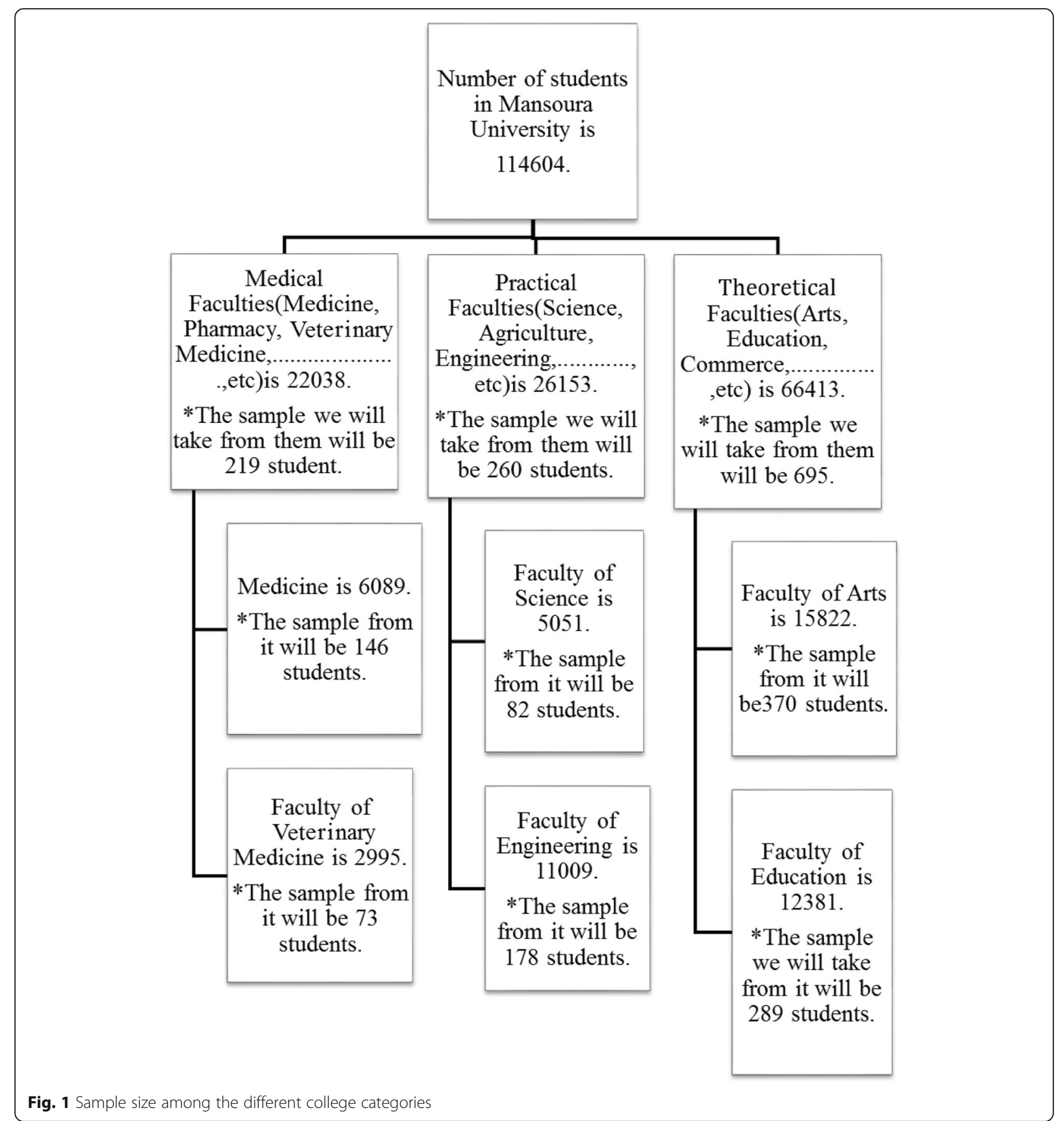

problems "Harmful drug use according to DSM-IV and ICD-10 that the treatment provider is interested in assessing" are diagnosed at a cut-off score of six points or more for men and two or more for women. Dependence is defined to be at a score of 25 or more for males and females as well [22]. The Arabic version of the DUDIT scale is a valid and reliable tool with sensitivity of .98 and a specificity of .90 [24].

\section{Statistical analysis}

Statistics analyzed using SPSS program version 16 (IBM Corporation, Chicago, IL, USA) [25]. A chi-squared test was used to test the significance of categorical data. Monte-Carlo was used to compare categorical data of more than 4 cells table. Mann-Whitney was applied to compare continuous data between 2 groups, while the Kruskal-Wallis test was used to compare non-normally 
distributed data between more than 2 groups. The crude odds ratio was calculated using the Epi-info program with a 95\% confidence interval. Logistic regression analysis was performed on significant variables in bivariate analysis. Adjusted odds ratios with 95\% confidence interval were calculated. $P$ value $\leq 0.05$ was considered statically significant.

\section{Results}

The total number of surveyed students was 1138; of them, 650 (57.1\%) were males. Two hundred nineteen (19.2\%) were medical students, 261(22.9\%) were from practical faculties, and 658(57.8\%) were from theoretical faculties. Five hundred seventy-three(50.4\%) were from the countryside. Their average age was $19.6 \pm 1.4$ (range, 17 to 25 years). There were 256 (22.5\%) smokers, 265 (23.3\%) had associated medical problems, 986 (86.6\%) did not work during the study, 971 (85.3\%) were using caffeine, and 1102 (96.8\%) were single (Table 1).

Of all students, $74(6.5 \%)$ were substance users, 50 (4.4\%) had drug-related problems, and $6(0.5 \%)$ were dependant users. Mono substance users of cannabis, tramadol, alcohol, benzo, and heroin were 18, 14, 10, 5, and 1 respectively; while for poly users, there were 10 for cannabis and tramadol; 12 for cannabis and alcohol; 3 for cannabis and inhalant; and 1 for cannabis, alcohol, and tramadol (Table 2).

There was a statistically significant difference in substance use among students of different study categories $(p \leq 0.001)$.The highest percentage was in the practical students 28 (10.7\%), who also showed a statistically significant higher percentage of non-problematic drug use according to DUDIT scores whose percentage was $8.3 \%$, $28.6 \%$, and $26.5 \%$ for medical, practical, and theoretical students, respectively. Besides, there was a higher percentage $(83.3 \%)$ of drug-related problems between the medical students and a higher percentage (10.7\%) of dependence between practical students. For mono substance, only alcohol showed a statistically significant difference $(p=0.04)$ between all students, while there was no statistically significant difference regarding polysubstance (Table 3).

Substance use among university students was significantly associated with age $\geq 20$ years $(p=\leq 0.001)$, male gender $(p=\leq 0.001)$, practical college students $(p=0.002)$, final school year students $(p=\leq 0.001)$, urban residence $(p=$ $0.03)$, smoking $(p=\leq 0.001)$, absence of medical problems $(p=0.04)$, working during study $(p=\leq 0.001)$, and marriage $(p=0.01)$ by univariate analysis (Table 4$)$.

Logistic regression analysis identified male sex, age $\geq 20$ years, smoking, and living in urban areas as independent risk factors for substance use among university students $(\mathrm{AOR}=1.9,4.1,1.8$, and 16.1, respectively) (Table 5).
Table 1 Socio-demographic characteristics of studied Egyptian students in Mansoura University

\begin{tabular}{|c|c|}
\hline Variables & $N$ [\%] [n= 1138] \\
\hline Age [mean $\pm S D]$ & $19.6 \pm 1.4$ \\
\hline$<20$ & $550[48.3]$ \\
\hline$\geq 20$ & $588[51.7]$ \\
\hline \multicolumn{2}{|l|}{ Sex } \\
\hline Male & $650[57.1]$ \\
\hline Female & $488[42.9]$ \\
\hline \multicolumn{2}{|l|}{ College type } \\
\hline Medical & 219 [19.2] \\
\hline Practical & $261[22.9]$ \\
\hline Theoretical & $658[57.8]$ \\
\hline \multicolumn{2}{|l|}{ Educational year } \\
\hline 1st year & $250[22]$ \\
\hline 2nd year & $257[22.6]$ \\
\hline 3rd year & $259[22.8]$ \\
\hline 4th year & $266[23.4]$ \\
\hline 5th year & $81[7.1]$ \\
\hline 6th year & $25[2.2]$ \\
\hline \multicolumn{2}{|l|}{ Residence } \\
\hline Urban & 565 [49.6] \\
\hline Rural & $573[50.4]$ \\
\hline \multicolumn{2}{|l|}{ Smoking } \\
\hline Yes & $256[22.5]$ \\
\hline No & $882[77.5]$ \\
\hline \multicolumn{2}{|l|}{ Medical problem } \\
\hline Yes & 265 [23.3] \\
\hline No & $873[76.7]$ \\
\hline \multicolumn{2}{|c|}{ Working during study } \\
\hline Yes & 152 [13.4] \\
\hline No & 986 [86.6] \\
\hline \multicolumn{2}{|c|}{ Caffeine consumption } \\
\hline Yes & 971 [85.3] \\
\hline No & $167[14.7]$ \\
\hline \multicolumn{2}{|l|}{ Marital status } \\
\hline Single & $1102[96.8]$ \\
\hline Married & $36[3.2]$ \\
\hline
\end{tabular}

All results are expressed as mean \pm standard deviation or number [percentage of total]. $N$ number

\section{Discussion}

In this study, 1183 Egyptian university students were surveyed. The prevalence of substance use was $6.5 \%$ and the prevalence of dependence was $0.5 \%$. The study revealed a high significance association of substance use to the field of study. The prevalence of substance use in students enrolled in practical educational programs was 
Table 2 Prevalence of substance use and DUDIT score among students in Mansoura University, Egypt

\begin{tabular}{ll}
\hline Parameter & $\boldsymbol{N}[\%]$ \\
\hline Substance use $[n=1138]$ & $74[6.5]$ \\
No & $1064[93.5]$ \\
Substance use according to DUDIT scores $[n=74]$ & \\
Non-drug-related problems & $18[1.6]$ \\
Drug-related problems & $50[4.4]$ \\
Dependence & $6[0.5]$ \\
Substance type [n=74] & \\
Mono substance & \\
Cannabis & $18[24.3]$ \\
Tramadol & $14[18.9]$ \\
Alcohol & $10[13.5]$ \\
Benzo & $5[6.8]$ \\
Heroin & $1[1.4]$ \\
Poly substance & \\
Cannabis and tramadol & $10[13.5]$ \\
Cannabis and alcohol & $12[16.2]$ \\
Cannabis and inhalant & $3[4.1]$ \\
Cannabis, alcohol, and tramadol & $1[1.4]$ \\
\hline Al & \\
\hline
\end{tabular}

All results are expressed as mean \pm standard deviation or number [percentage of total]. $N$ number twofold higher than in medical or theoretical students. Practical students also showed the highest rate of drug dependence. Male sex, age $\geq 20$ years, smoking, and urban living have been identified as independent risk factors of substance use among Egyptian university students.

In the current study, $10.3 \%$ of male students utilized substances, whereas only $1.4 \%$ of female students did. This finding is in line with the findings of a recent national study in Egypt, which demonstrated that $15.8 \%$ of males and $2.2 \%$ of females from various professions have used substances at least once in their lives [3]. This finding is also consistent with other studies [7, 9, 11, 26-28]. This low prevalence of substance use among female individuals of Egyptian university students could be due to social stigma, which may cause them to deny substance use, or it could be due to the higher social tolerability of substance use among males [29].

Another interesting finding in our study was that $22.5 \%$ of the participant students were smokers. This is consistent with a study conducted in the USA in which smokers were less than 20\% [9] and in North Carolina and Virginia smokers were 50\% [30]. Approximately, the same was found in other studies as [1, 7, 13, 31, 32].

Looking to cigarette smoking as a major factor associated with substance use, our study found that $83.8 \%$ of substance users are smokers and this is consistent with

Table 3 Prevalence of substance use in medical, practical and theoretical students and DUDIT scores

\begin{tabular}{|c|c|c|c|c|}
\hline Parameter & $\begin{array}{l}\text { Medical students } \\
{[n=219]} \\
N[\%]\end{array}$ & $\begin{array}{l}\text { Practical students } \\
{[n=261]} \\
N[\%]\end{array}$ & $\begin{array}{l}\text { Theoretical students } \\
{[n=658]} \\
N[\%]\end{array}$ & $\begin{array}{l}P \text { value } \\
\text { (Monte-Carlo test) }\end{array}$ \\
\hline \multicolumn{5}{|l|}{ Substance use } \\
\hline Users & $12[5.5]$ & 28 [10.7] & $34[5.2]$ & 0.007 \\
\hline \multicolumn{5}{|c|}{ Substance use according to DUDIT scores } \\
\hline Non-drug-related problem [users] & $1[8.3]$ & $8[28.6]$ & $9[26.5]$ & $\leq 0.001$ \\
\hline Drug-related problems & 10 [83.3] & $17[60.7]$ & $23[67.6]$ & \\
\hline Dependence & $1[8.3]$ & $3[10.7]$ & $2[5.9]$ & \\
\hline \multicolumn{5}{|l|}{ Substance type } \\
\hline \multicolumn{5}{|l|}{ Mono substance } \\
\hline Cannabis & - & $6[2.3]$ & $12[1.8]$ & 0.1 \\
\hline Tramadol & $4[1.8]$ & $6[2.3]$ & $4[0.6]$ & 0.07 \\
\hline Alcohol & $3[1.4]$ & $5[1.9]$ & $2[0.3]$ & 0.04 \\
\hline Benzo & $3[1.4]$ & $1[0.4]$ & $1[0.2]$ & 0.06 \\
\hline Heroin & - & - & $1[0.2]$ & 0.9 \\
\hline \multicolumn{5}{|l|}{ Poly substance } \\
\hline Cannabis and tramadol & $1[0.5]$ & $2[0.8]$ & 7 [1.1] & 0.8 \\
\hline Cannabis and alcohol & $1[0.5]$ & $6[2.3]$ & $5[0.8]$ & 0.07 \\
\hline Cannabis and inhalant & - & $1[0.4]$ & $2[0.3]$ & 0.9 \\
\hline Cannabis, alcohol, and tramadol & - & $1[0.4]$ & - & 0.4 \\
\hline
\end{tabular}

$P$ value is assessed via Monte-Carlo test. $P$ value $\leq 0.05$ is considered statistically significant. $N$ number 
Table 4 Bivariate analysis of factors associated with substance use

\begin{tabular}{|c|c|c|c|c|}
\hline Variables & Total & $\begin{array}{l}\text { Substance user } \\
N[\%]\end{array}$ & $\begin{array}{l}P \text { value } \\
\text { (Chi-square) }\end{array}$ & $\begin{array}{l}\text { COR [95\% Cl] } \\
\text { (Epi-info program) }\end{array}$ \\
\hline Overall & 1138 & $74[6.5]$ & - & - \\
\hline \multicolumn{5}{|l|}{ Age } \\
\hline$<20$ & 550 & $21[3.8]$ & $\leq 0.001$ & $1 \mathrm{r}$ \\
\hline$\geq 20$ & 588 & 53 [9] & & $2.5[1.5-4.2]$ \\
\hline \multicolumn{5}{|l|}{ Sex } \\
\hline Male & 650 & $67[10.3]$ & $\leq 0.001$ & $7.8[3.6-17.4]$ \\
\hline Female & 488 & $7[1.4]$ & & $1 \mathrm{r}$ \\
\hline \multicolumn{5}{|l|}{ College type } \\
\hline Medical & 219 & $12[5.5]$ & 0.9 & $1.1[0.5-2.09]$ \\
\hline Practical & 261 & 28 [10.7] & 0.002 & $2.2[1.3-3.7]$ \\
\hline Theoretical & 658 & $34[5.2]$ & & $1 \mathrm{r}$ \\
\hline \multicolumn{5}{|l|}{ Educational year } \\
\hline 1st and 2 nd year & 507 & $13[2.6]$ & & $1 r$ \\
\hline $3 r d$ year & 259 & $12[4.6]$ & 0.1 & $1.8[0.8-4.1]$ \\
\hline 4th year & 266 & $33[12.4]$ & $\leq 0.001$ & $5.4[2.8-10.4]$ \\
\hline 5th and 6th year & 106 & 16 [15.1] & $\leq 0.001$ & $6.7[3.1-14.5]$ \\
\hline \multicolumn{5}{|l|}{ Residence } \\
\hline Urban & 565 & $46[8.1]$ & 0.03 & $1.7[1.1-2.8]$ \\
\hline Rural & 573 & $28[4.9]$ & & $1 \mathrm{r}$ \\
\hline \multicolumn{5}{|l|}{ Smoking } \\
\hline Yes & 256 & $62[24.2]$ & $\leq 0.001$ & 23.1 [12.2-43.8] \\
\hline No & 882 & $12[1.4]$ & & $1 \mathrm{r}$ \\
\hline \multicolumn{5}{|l|}{ Medical problem } \\
\hline Yes & 265 & $10[3.8]$ & 0.04 & $1 \mathrm{r}$ \\
\hline No & 873 & 64 [7.3] & & 2.01 [1.02-3.9] \\
\hline \multicolumn{5}{|l|}{ Working during study } \\
\hline Yes & 152 & 21 [13.8] & $\leq 0.001$ & $2.8[1.6-4.8]$ \\
\hline No & 986 & $53[5.4]$ & & $1 \mathrm{r}$ \\
\hline \multicolumn{5}{|l|}{ Marital status } \\
\hline Single & 1102 & 68 [6.2] & 0.01 & $1 r$ \\
\hline Married & 36 & 6 [16.7] & & $3.04[1.2-7.5]$ \\
\hline
\end{tabular}

COR crude odds ratio which was calculated using Epi-info program. Data are expressed as mean \pm standard deviation; $P$ value is assessed via Chi-square. $P$ value $\leq$ 0.05 is considered statistically significant, $N$ number

studies as $[7,9,33,34]$. The high prevalence of smoking among substance users may refer to smoking as a predictor of substance use besides the easy accessibility and legalized use of smoking.

Utilizing substances is one of the most devastating public health issues especially among university students as they are a highly vulnerable group for this problem. In this study, the prevalence of substance use was $6.5 \%$, which is by a study conducted in Turkey where the prevalence was 6.3\% [35], and slightly higher than the prevalence of $5 \%$ among a similar population in Egypt [13]. However, much higher rates were reported in other studies such as $28.6 \%$ in Ethiopia, $3542.8 \%$ among health care students in Nepal [1], and 69.8\% in Kenya [36].

This low prevalence in our study might be due to different sampling techniques or due to cultural and societal differences.

Cannabis is the most commonly used substance by about $24.3 \%$ of the participant users followed by tramadol, alcohol, benzodiazepines, and heroin with the percentage of $8.9 \%, 13.5 \%, 6.8 \%$, and $1.4 \%$ respectively. This is in agreement with other studies performed in Egypt, Sudan, and Kuwait [7-9]. 
Table 5 Logistic regression of factors associated with substance abuse

\begin{tabular}{|c|c|c|c|}
\hline Parameter & $B$ & $P$ value & AOR $[95 \% \mathrm{Cl}]$ \\
\hline \multicolumn{4}{|l|}{ Age } \\
\hline$<20$ & 0.6 & 0.03 & $1.9[1.1-3.3]$ \\
\hline \multicolumn{4}{|l|}{$\geq 20$} \\
\hline \multicolumn{4}{|l|}{ Sex } \\
\hline Male & 1.4 & 0.001 & $4.1[1.8-9.3]$ \\
\hline Female & & & $1 \mathrm{r}$ \\
\hline \multicolumn{4}{|l|}{ Residence } \\
\hline Urban & 0.58 & 0.03 & $1.8[1.05-3.1]$ \\
\hline Rural & & & $1 r$ \\
\hline \multicolumn{4}{|l|}{ Smoking } \\
\hline Yes & 2.7 & $\leq 0.001$ & 16.1 [8.4-30.8] \\
\hline No & & & $1 \mathrm{r}$ \\
\hline
\end{tabular}

$\beta$ regression coefficient, $A O R$ adjusted odds ratio, $r$ reference group, $C l$ confidence interval, $P$ value is significant if $\leq 0.05$

This pattern is also consistent with the latest Egyptian national survey, where the most misused substance was cannabis (77\%) [3]. The increased prevalence of cannabis use could be linked to a recent decline in public awareness of the risk associated with its use. Several researchers have found that a low-risk perception is linked to a higher likelihood of drug usage [37-40]. Tramadol came second as the most consumed substance after cannabis in our participants and has become a public health issue in Egypt. Numerous research looked at its widespread use among adolescents [41], and its ramifications among substance use patients [42].

Among all students in our study, $10.7 \%$ of practical students and 5.5\% and 5.2\% of medical and theoretical students, respectively, have been identified as substance users. In the study performed by Bassiony and colleagues in 2018, the percentages of substance use among practical and theoretical colleges were $11.8 \%$ and $43 \%$, respectively [7]. In another study published in the same year by the same group, the percentage was $34.1 \%$ among practical and $65.9 \%$ among theoretical students [21].

Regarding the most used substances in each category, tramadol is the most commonly used substance among medical students $(1.8 \%)$, cannabis and tramadol came on top with the same percentage (2.3\%) among practical students. Among theoretical college students, cannabis was the most used substance $(1.8 \%)$. On the other hand, in a study done among Zagazig University students, the most used substances among practical students (including medical) were alcohol, tramadol [7], and in another study in the UK, cannabis came on top among medical students [43].
Tramadol is used as an analgesic for both acute and chronic pain and arbitrates analgesia as an opioid receptor agonist and synergistically as a serotonin-norepinephrine reuptake inhibitor [44]. In Egypt, there is a misconception that opioids enhance cognitive and sexual performances and delay physical exhaustion [45]. This could explain that medical and practical students mainly use substances to cope with the study stress or to get more power to enhance their physical and mental performance.

Practical students had the highest dependence percent $(10.7 \%)$ in the current study. While medical students had the highest rate of drug-related problems (83.3\%), Bajwa and colleagues [8] reported the highest percentage of drug-related problems to be among practical students as medical students counted as practical while the highest percentage of dependence was found among theoretical students. On the other hand, Bassiony and colleagues [21] found the highest drug-related problem percentage among theoretical students. The knowledge of medical students about the hazards of substance use and its devastating effect on health could be the cause of their low percentage of dependence.

Educational and preventive programs should be established as early as possible for high school students to increase their orientation regarding substance use and its estimated hazardous effects. Rehabilitation programs should be applied to students who have problems with substance use to minimize consequences.

\section{Strengths and limitations of the study}

It is one of the earliest studies in Egypt done to measure the prevalence of substance use among university students, describe its risk factors among practical, theoretical, and medical students. Our results cannot be interpreted without taking into account a few study limitations: (1) this study was an observational crosssectional study, so other longitudinal studies are needed in the future to determine the causative nature of the associations between substance use and its correlates; (2) the study was intuitively answered by the students, which could lead to both selection and recall biases; (3) using self-reported scales without using structured interview might overestimate the prevalence of substance in university students; and (4) the results of the study cannot be generalized to the whole community as it is done on university students. (5) Detailed history taking of substance use including onset, duration of substance use, cause of start, continued use of substance, and its relation to academic achievements were not included. (6) Clinical assessment of psychiatry disorders using a structured clinical interview as associated factor of substance use was not conducted in the study. 


\section{Conclusions}

In total, $6.5 \%$ of university students admitted using drugs at some point in their life with the percentage of $5.5 \%$, $10.7 \%$, and $5.2 \%$ among medical, practical, and theoretical students respectively. In total, using the mono substance is more than using poly substances in which cannabis, tramadol, and alcohol were the most often utilized substances. The most commonly used substance among medical students is tramadol; cannabis and tramadol come on the top among the practical students, and by looking to the theoretical college students, cannabis is the most used substance. Totally, according to DUDIT around $4.4 \%$ and $0.5 \%$ are complaining of drug-related problems and dependence respectively. The highest percentage of drug-related problems is among medical students while dependence is the highest among practical students. Older age, male sex, urban residence, and cigarette smoking were all risk variables for substance use. These results should be considered in future substance preventive programs.

\section{Abbreviations}

DUDIT: Drug use disorders identification test; USA: United States of America; AUDIT: Alcohol use disorders identification test; WHO: World Health Organization; DSM: Diagnostic and Statistical Manual of Mental Disorders; ICD: International Classification of Disease; SPSS: Statistical Package for the Social Sciences

\section{Acknowledgements}

We are grateful to all university students that share in the research.

\section{Authors' contributions}

MK: Data collection and drafting the manuscript. ZG: Supervision and coordination of all research activities, revision of final draft for important intellectual contents. ME: Conception of research idea, revision of results, draft manuscript for intellectual contents. All authors read the final manuscript and agreed about its contents. All authors have read and approved the manuscript.

\section{Funding}

None

\section{Availability of data and materials}

Data are available upon request from the corresponding author.

\section{Declarations}

\section{Ethics approval and consent to participate}

In agreement with the Declaration of Helsinki, the proposal was approved by the Institutional Review Board (IRB) of the Faculty of Medicine, Mansoura University (Code Number: MS/18.09.292). Written informed consent was obtained from all students who were willing to endorse the study after ensuring confidentiality.

\section{Consent for publication}

Not applicable.

\section{Competing interests}

The authors declare that they have no competing interests.

\section{Author details}

${ }^{1}$ Psychiatry Department, Port-Said Mental Health Hospital, Port Said, Egypt. ${ }^{2}$ Psychiatry Department, Faculty of Medicine, Mansoura University, Mansoura 35516, Egypt.
Received: 27 July 2021 Accepted: 4 September 2021

Published online: 15 October 2021

\section{References}

1. Panthee B, Panthee S, Gyawali S, Kawakami N (2017) Prevalence and correlates of substance use among health care students in Nepal: a crosssectional study. BMC Public Health 17(1):950. https://doi.org/10.1186/s12889017-4980-6

2. World Drug Report U. World Drug Report, Youth. 30 Sep 201. New York, United States: United Nations; 2018. 1-62 p.

3. Hamdi E, Sabry N, Sedrak A, Khowailed A, Loza N, Rabie M, Ramy H (2016) Sociodemographic indicators for substance use and abuse in Egypt. J Addiction Prevention 4(1):8

4. Viney S. As drug addiction rises in Cairo, experts offer recommendations.

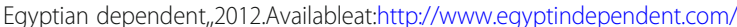
news/drug-addiction-rises Cairo-experts-offer-recommendations. Accessed June 15, 2017.

5. Rabie M, Shaker NM, Gaber E, El-Habiby M, Ismail D, El-Gaafary M, Lotfy A Sabry N, Khafagy W, Muscat R (2020) Prevalence updates of substance use among Egyptian adolescents. Middle East Curr Psychiatry 27(1):4. https://doi. org/10.1186/s43045-019-0013-8

6. Skidmore CR, Kaufman EA, Crowell SE (2016) Substance use among college students. Child Adolesc Psychiatr Clin 25(4):735-753. https://doi.org/10.1016/ j.chc.2016.06.004

7. Bassiony MM, Salah El-Deen G, Abdelghani M, Youssef UM, Hassan MS, ElGohari H (2018) Addressing prevalence and correlates among a sample of Egyptian university students who suffer from substance use disorders. Addict Disord Treat 17(3):114-123. https://doi.org/10.1097/ADT. 0000000000000131

8. Bajwa HZ, Al-Turki ASA, Dawas AMK, Behbehani MQ, Al-Mutairi AMA, AlMahmoud S, Shukkur M, Thalib L (2013) Prevalence and factors associated with the use of illicit substances among male university students in Kuwait. Med Princ Pract 22(5):458-463. https://doi.org/10.1159/000350609

9. Osman T, Victor C, Abdulmoneim A, Mohammed H, Abdalla F, Ahmed A, Mohammed W (2016) Epidemiology of substance use among university students in Sudan. J Addict 2016:2476164. https://doi.org/1 $0.1155 / 2016 / 2476164$

10. Evans-Polce R, Lanza S, Maggs J (2016) Heterogeneity of alcohol, tobacco, and other substance use behaviors in US college students: a latent class analysis. Addict Behav 53:80-85. https://doi.org/10.1016/j.addbeh.2015.10.010

11. Fernández-Villa T, Molina AJ, Amezcua-Prieto C, Mateos R, Cancela JM, Delgado-Rodríguez M et al (2019) Drug use, family support and related factors in university students. A cross-sectional study based on the uniHcos Project data. Gac Sanit 33(2):141-147. https://doi.org/10.1016/j.gaceta.2017.1 0.019

12. Schilling $L$, Zeeb $H$, Pischke $C$, Helmer S, Schmidt-Pokrzywniak A, Reintjes R et al (2017) Licit and illicit substance use patterns among university students in Germany using cluster analysis. Subst Abuse Treat Prev Policy 12(1):44

13. Meray MS, Ahmed FH, Rania AR (2016) Study of drug abuse among university students in Sohag, Egypt. J Forensic Toxicol Med Leg Anal 1(2): 19-23

14. Musyoka CM, Mbwayo A, Donovan D, Mathai M (2020) Alcohol and substance use among first-year students at the University of Nairobi, Kenya: prevalence and patterns. PloS one 15(8):e0238170. https://doi.org/10.1371/ journal.pone. 0238170

15. Substance Abuse and Mental Health Services Administration. (2018). Key substance use and mental health indicators in the United States: Results from the 2017 National Survey on Drug Use and Health (HHS Publication No. SMA 18-5068, NSDUH Series H-53). Rockville: Center for Behavioral Health Statistics and Quality, Substance Abuse and Mental Health Services Administration. Retrieved from https://www.samhsa.gov/data/

16. European Monitoring Centre for Drugs. European Drug Report [Internet]. European Union Publications Office. 2019. 1-94 p. Available from: http://www.emcdda.europa.eu/system/files/publications/4541/TDA T17001ENN.pdf_en.

17. Kassa A, Taddesse F, Yilma A (2014) Prevalence and factors determining psychoactive substance (PAS) use among Hawassa University (HU) undergraduate students, Hawassa Ethiopia. BMC Public Health 14(1):1-7. https://doi.org/10.1186/1471-2458-14-1044 
18. Nwanna UK, Sulayman AA, Oluwole I, Kolawole AK, Komuhang G, Lawoko S (2018) Prevalence \& risk factors for substance abuse among university students in Kampala, Uganda. Int J Med Res Public Heal 2(1):1-13

19. Soueif MI, Darweesh ZA, Hannourah MA, el-Sayfd AM, Yunis FA, Taha HS (1986) The extent of drug use among Egyptian male university students. Drug Alcohol Depend 18(4):389-403. https://doi.org/10.1016/0376-8716(86)90104-3

20. El-Ghonemy SH, El-Din MH, Mowafy A, Hasan H, El Ghamry RH (2021) Sociodemographic Correlates of Substance Use in a Sample of Egyptian Female University Students. Addict Disord Treat. https://doi.org/10.1097/A DT.0000000000000275

21. Bassiony MM, Abdelghani M, Salah El-Deen GM, Hassan MS, El-Gohari H, Youssef UM (2018) Opioid use disorders attributed to tramadol among Egyptian university students. J Addict Med 12(2):150-155. https://doi.org/1 0.1097/ADM.0000000000000380

22. Berman AH, Bergman H, Palmstierna T, Schlyter F (2004) Evaluation of the drug use disorders identification test (DUDIT) in criminal justice and detoxification settings and in a Swedish population sample. Eur Addict Res 11(1):22-31. https://doi.org/10.1159/000081413

23. Saunders JB, Aasland OG, Babor TF, De la Fuente JR, Grant M (1993) Development of the alcohol use disorders identification test (AUDIT): WHO collaborative project on early detection of persons with harmful alcohol consumption-II. Addiction 88(6):791-804. https://doi.org/10.1111/j.13600443.1993.tb02093.x

24. Sfendla A, Zouini B, Lemrani D, Berman AH, Senhaji M, Kerekes N (2017) Psychometric properties of the Arabic version of the drug use disorders identification test (DUDIT) in clinical, prison inmate, and student samples. Int J Behav Med 24(2):280-287. https://doi.org/10.1007/s12529-016-9623-2

25. SPSS Inc. SPSS for Windows, version 16.0. Chicago, IL, SPSS Inc. 2007. Available at: www.unimuenster.de/imperia/md/content/ziv/service/software/spss/ha ndbuecher/English/spss_brief_guide_16.0.pdf. Accessed January 9, 2016.

26. Alebachew W, Semahegn A, Ali T, Mekonnen H (2019) Prevalence, associated factors and consequences of substance use among health and medical science students of Haramaya University, eastern Ethiopia, 2018: a cross-sectional study. BMC Psychiatry 19(1):343. https://doi.org/10.1186/s12 888-019-2340-z

27. Abbasi-Ghahramanloo A, Fotouhi A, Zeraati H, Rahimi-Movaghar A (2015) Prescription drugs, alcohol, and illicit substance use and their correlations among medical sciences students in Iran. Int J High Risk Behav Addict 4(1): e21945. https://doi.org/10.5812/ijhrba.21945

28. Ayala EE, Roseman D, Winseman JS, Mason HR (2017) Prevalence, perceptions, and consequences of substance use in medical students. Med Educ Online 22(1):1392824. https://doi.org/10.1080/10872981.2017.1392824

29. Tsvetkova L, Antonova N (2013) The prevalence of drug use among university students in St. Petersburg, Russia. Psychology in Russia: State of the Art 6(12):86-94. https://doi.org/10.11621/pir.2013.0108

30. Suerken CK, Reboussin BA, Egan KL, Sutfin EL, Wagoner KG, Spangler J, Wolfson M (2016) Marijuana use trajectories and academic outcomes among college students. Drug Alcohol Depend 162:137-145. https://doi. org/10.1016/j.drugalcdep.2016.02.041

31. Adere A, Yimer NB, Kumsa H, Liben ML (2017) Determinants of psychoactive substances use among Woldia University students in Northeastern Ethiopia. BMC Res Notes 10(1):441. https://doi.org/10.1186/s13104-017-2763-x

32. Mekonen T, Fekadu W, Mekonnen TC, Workie SB (2017) Substance use as a strong predictor of poor academic achievement among university students. Psychiatry J 2017:7517450. https://doi.org/10.1155/2017/7517450

33. Negm MG, Fouad AA (2014) Prevalence of substance abuse among adolescent school students in Zagazig. Egypt J Psychiatry 35(3):161. https:// doi.org/10.4103/1110-1105.144344

34. Loffredo CA, Boulos DNK, Saleh DA, Jillson IA, Garas M, Loza N, Samuel P, Shaker YE, Ostrowski M-J, Amr S (2015) Substance use by Egyptian youth: current patterns and potential avenues for prevention. Subst Use Misuse 50(5):609-618. https://doi.org/10.3109/10826084.2014.997391

35. Bakar C, Gündogar D, Ozisik Karaman HI, Maral I (2013) Prevalence and related risk factors of tobacco, alcohol, and illicit substance use among university students. Eur J Psychiatry 27(2):97-110

36. Atwoli L, Mungla PA, Ndung'u MN, Kinoti KC, Ogot EM (2011) Prevalence of substance use among college students in Eldoret, western Kenya. BMC Psychiatry 11(1):1-9. https://doi.org/10.1186/1471-244X-11-34

37. Lopez-Quintero C, Neumark Y (2010) Effects of risk perception of marijuana use on marijuana use and intentions to use among adolescents in Bogota.
Colombia. Drug Alcohol Depend 109(1-3):65-72. https://doi.org/10.1016/j. drugalcdep.2009.12.011

38. Kilmer JR, Hunt SB, Lee CM (2007) Marijuana use, risk perception, and consequences: is perceived risk congruent with reality? Addict Behav 32(12): 3026-3033

39. Merrill RM (2015) Use of marijuana and changing risk perceptions. Am J Health Behav 39(3):308-317

40. Beck F, Legleye S, Chomynova P (2014) A quantitative exploration of attitudes out of line with the prevailing norms toward alcohol, tobacco, and cannabis use among European students. Subst Use Misuse. 49(7):877-890. https://doi.org/10.3109/10826084.2014.889910

41. Bassiony MM, Salah El-Deen GM, Yousef U (2015) Adolescent tramadol use and abuse in Egypt. Am J Drug Alcohol Abuse. 41(3):206-211. https://doi. org/10.3109/00952990.2015.1014959

42. Bassiony MM, Youssef UM, Hussein RA (2016) Psychiatric comorbidity among Egyptian patients with opioid use disorders attributed to tramadol. J Addict Med 10(4):262-268. https://doi.org/10.1097/ADM.0000000000000231

43. Bogowicz P, Ferguson J, Gilvarry E, Kamali F, Kaner E, Newbury-Birch D (2018) Alcohol and other substance use among medical and law students at a UK university: a cross-sectional questionnaire survey. Postgrad Med J 94(1109):131-136. https://doi.org/10.1136/postgradmedj-2017-135136

44. Rostam-abadi Y, Gholami J, Amin-Esmaeili M, Safarcherati A, Mojtabai R, Ghadirzadeh MR et al (2020) Tramadol use and public health consequences in Iran: a systematic review and meta-analysis. Addiction 115(12):2213-2242. https://doi.org/10.1111/add.15059

45. El- Hadidy, M. A., \&El-Gilany, A. H. (2014) Physical and sexual wellbeing during and after tramadol dependence. Middle East Curr Psychiatry. 21(3): 148-151. https://doi.org/10.1097/01.XME.0000449839.69324.71

\section{Publisher's Note}

Springer Nature remains neutral with regard to jurisdictional claims in published maps and institutional affiliations.

\section{Submit your manuscript to a SpringerOpen ${ }^{\odot}$ journal and benefit from:}

- Convenient online submission

- Rigorous peer review

- Open access: articles freely available online

- High visibility within the field

- Retaining the copyright to your article

Submit your next manuscript at $>$ springeropen.com 